\title{
A pilot open trial of UNITE-BED: A couple-based intervention for binge-eating disorder
}

\author{
Cristin D. Runfola $\mathrm{PhD}^{1,2}$ (1) | Jennifer S. Kirby $\mathrm{PhD}^{2}$ | Donald H. Baucom $\mathrm{PhD}^{3}$ | \\ Melanie S. Fischer PhD ${ }^{3}$ | Brian R. W. Baucom PhD ${ }^{4}$ | Camden E. Matherne PhD ${ }^{2}$ | \\ Kimberly Z. Pentel MA ${ }^{3}$ | Cynthia M. Bulik PhD $2,5,6$
}

${ }^{1}$ Department of Psychiatry and Behavioral Sciences, Stanford University, Stanford, California

${ }^{2}$ Department of Psychiatry, University of North Carolina at Chapel Hill, Chapel Hill, North Carolina, US

${ }^{3}$ Department of Psychology and Neuroscience, University of North Carolina at Chapel Hill,

Chapel Hill, North Carolina, US

${ }^{4}$ Department of Psychology, University of Utah, Salt Lake City, Utah

${ }^{5}$ Department of Nutrition, University of North Carolina at Chapel Hill, Chapel Hill, North Carolina

${ }^{6}$ Department of Medical Epidemiology and Biostatistics, Karolinska Institutet, Stockholm, Sweden

Correspondence

Cynthia Bulik, Department of Psychiatry, University of North Carolina at Chapel Hill, Chapel Hill, North Carolina, USA.

Email: cbulik@med.unc.edu

Funding information

Global Foundation for Eating Disorders; Hilda and Preston Davis Foundation; Swedish

Research Council

\begin{abstract}
Objective: To evaluate the feasibility, acceptability, and preliminary efficacy of a couple-based intervention for binge-eating disorder (BED), called UNiting couples In the Treatment of Eating disorders-BED edition (UNITE-BED).

Method: In an open pilot trial, 11 couples in which one or both adult partners had a diagnosis of DSM-5 threshold or sub-threshold BED participated in 22 weekly sessions of UNITE-BED. Patients also received individual treatment, outside of the context of the trial. Couples completed measures on treatment satisfaction, eating disorder symptom severity, depression, anxiety, emotion regulation, and relational functioning at post-treatment and 3-month follow-up. Statistical analyses were conducted to identify change over the course of treatment.

Results: UNITE was feasible and acceptable to the majority of couples ( $9 \%$ dropout; high satisfaction ratings). Objective binge abstinence was $81.8 \%$ and subjective binge abstinence was $45.5 \%$ by post-treatment. Patient binge-eating symptomatology reduced over the course of treatment with results maintained at follow up. Patients' depression symptoms decreased and patients' emotion regulation improved at both time points.

Discussion: Including partners in treatment for BED may be beneficial. Results support further evaluation of the efficacy of couple-based interventions for BED in larger randomizedcontrolled trials.
\end{abstract}

\section{KEYWORDS}

binge eating, binge-eating disorder, couple, intervention, treatment

\section{1 | INTRODUCTION}

Eating disorders (EDs) exact an emotional and financial toll on patients, families, and partners (Agh et al., 2016). Family-based treatment leverages families in improving outcomes for youth EDs (Lock, 2015); however, typical treatment for adult EDs is individual psychotherapy and outcomes remain modest (Grilo, 2017).

To expand intervention options for adult EDs, we created a suite of couple-based treatments incorporating partners in a developmentally appropriate manner. Our first treatment, "Uniting Couples in the treatment of Anorexia Nervosa (UCAN)" (Baucom et al., 2017), yielded

Cristin D. Runfola and Jennifer S. Kirby are co-first authors lower drop-out (10\%) than most adult anorexia nervosa trials ( $25 \%$; Bulik, Berkman, Brownley, Sedway, \& Lohr, 2007); increased weight gain notably; decreased anxiety and depression; and improved relationship functioning. Herein, we present pilot results of "UNiting couples In the Treatment of Eating disorders-Binge-Eating Disorder edition (UNITE-BED)."

Up to $77 \%$ of individuals with BED are married or cohabitating (Schlup, Meyer, \& Munsch, 2010). Emerging data suggest that BED is associated with interpersonal challenges (Arcelus, Haslam, Farrow, \& Meyer, 2013; Blomquist, Ansell, White, Masheb, \& Grilo, 2012), and emotion regulation deficits that may influence symptom maintenance or relapse (Jones, Lindekilde, Lübeck, \& Clausen, 2015; Leehr et al., 2015). In clinical studies of ED outcomes, pre-treatment interpersonal 
problems predict poorer treatment response and higher dropout (Jones et al., 2015). In addition, interpersonal stressors are common binge triggers (Hilbert, Vogele, Tuschen-Caffier, \& Hartmann, 2011). Notably, such stressors frequently occur in women with BED, as they report lower marital satisfaction, less frequent positive interaction, and increased negative interaction in their relationships than non-ill women (Whisman, Demetyeva, Baucom, \& Bulik, 2012). Partners also experience challenges as they find it difficult to understand EDs, struggle with ED-related secrecy, and express powerlessness and ineffectiveness (Linville, Cobb, Shen, \& Stadelman, 2015).

Partners need guidance on how to facilitate change constructively. Couple-based treatments target potentially detrimental interpersonal dynamics and may improve outcomes, reduce relapse (Linville et al., 2015), and improve patient and partner quality of life (Macdonald et al., 2014). UNITE-BED targets BED psychopathology, co-occurring symptoms, and relationship functioning (Kirby, Runfola, Fischer, Baucom, \& Bulik, 2015; Kirby, Runfola, Fischer, Baucom, \& Bulik, 2016) by integrating core cognitive-behavioral therapy (CBT) for BED principles (Fairburn, Cooper, \& Shafran, 2003) with cognitivebehavioral couple therapy interventions (CBCT; Epstein \& Baucom, 2002). For details of UNITE-BED, see online Supplementary Information UNITE-BED Subheaders I-II.

We tested UNITE-BED in an open pilot trial, hypothesizing that it would be feasible and acceptable to couples, and would yield low dropout [based on UCAN (Baucom et al., 2017)]. We predicted significant patient improvement at post-treatment and 3-month follow-up in: (a) binge-eating frequency and overall ED severity; (b) depression, anxiety, and emotion regulation; and (c) relationship functioning. We also expected partner improvement on depression, anxiety, and relationship functioning.

\section{2 | METHOD}

We included 11 couples with an index patient with DSM-5 (APA, 2013) BED or sub-threshold BED, who were in a committed relationship for $\geq 6$ months. The study was approved by the University of North Carolina at Chapel Hill Institutional Review Board.

\section{1 | Treatment}

Participants received UNITE-BED at the UNC Center of Excellence for Eating Disorders. All participants with BED were enrolled in individual treatment independent of the trial and met with the study psychiatrist to verify medical stability. Additional detail on the rationale for individual treatment is available in Supplementary Information UNITE-BED Subheader III. Participants could also continue nutritional counseling and medication management. Study clinicians coordinated care with other providers as needed.

\subsection{1 | UNITE-BED}

UNITE-BED is a manualized, weekly 22 -session couple-based intervention, incorporating topics relevant to BED and couple functioning (see Supplementary Information Table S1 for a list of UNITE manual components by session). UNITE-BED therapists were licensed psychologists or advanced doctoral students with specialized training in ED treatment, CBCT, and UNITE-BED. To ensure treatment fidelity, all sessions were recorded and reviewed by a supervising clinician (JK or DB) who conducted weekly individual and group supervision.

\section{3 | MATERIALS}

Patients and partners were assessed at pre-treatment, post-treatment, and 3-month follow-up. Couples received $\$ 50$ for assessments. Height and weight were measured for body mass index $\left[\mathrm{BMI}(\mathrm{kg}) /(\mathrm{m})^{2}\right]$.

All measures met ICMJE guidelines (2010) inclusion criteria and sources for all measures used are available in Supplementary Information UNITE-BED Subheader IV. To establish psychiatric diagnoses in patients and partners, we used the Structured Clinical Interview for DSM-IV-Patient Edition and SCID-Nonpatient Edition with an expanded Module $\mathrm{H}$ (updated for DSM-5).

\section{1 | Eating-disorder pathology}

Eating-Disorder Examination (EDE); Binge-Eating Scale (BES); and the Yale-Brown Obsessive Compulsive Scale Modified for Binge Eating ( $Y$ BOCS-BE). EDE items assessing the number of objective (OBE) and subjective (SBE) binge episodes determined binge-eating abstinence (no episodes over 28 days) and binge-eating remission (no episodes over the prior 3 months) at post-treatment and 3-month follow-up.

\section{2 | Mood and psychological functioning}

Beck Depression Inventory-II (BDI-II); Beck Anxiety Inventory (BAI); Difficulties in Emotion Regulation Scale (DERS)-8-item modified version (DERS-partner) assessed perceptions of one's partner's emotion regulation ability. Higher scores reflect greater emotion regulation difficulties.

\section{3 | Relationship adjustment and communication}

Dyadic Adjustment Scale effectively predicts relationship dissolution; Communication Patterns Questionnaire Short Form (CPQ-SF) measures demand/withdraw roles and constructive communication (adapted for BED); Marital Satisfaction Inventory, Revised (MSI-R)-Problem-solving and Affective Communication subscales. On DAS-32, a total $<100$ suggests clinically significant relationship distress; higher scores indicate less distress.

\section{4 | Treatment satisfaction and acceptability}

Client Satisfaction Questionnaire-Revised (CSQ-8-Revised). High scores indicate greater satisfaction.

\section{5 | Statistics}

We applied paired sample $t$ tests for patient measures and two-way, within-subjects ANOVAs for measures completed by patients and partners. Significant interactions in ANOVAs were decomposed using post hoc paired sample $t$ tests separately for patients and partners. All 
analyses were intent-to-treat $(N=11)$ (White, Horton, Carpenter, \& Pocock, 2011), when data were available (one couple did not complete all post-treatment measures). We adopted a $p$-value of $<.05$. Effect sizes were calculated (see Table 1 footer for details).

\section{4 | RESULTS}

Patients' mean age was 48.3 years $(S D=12.85)$; $9 / 11$ were women and $10 / 11$ were Caucasian. All had at least a college education (7/11 had post-graduate degrees). Individual incomes ranged from $<\$ 5,000$ to $\$ 100-250,000 /$ year. All were in heterosexual relationships and together for a mean of 17.3 years $(S D=14.5)$, with seven married, and 10 cohabitating. Mean patient BMI was $37.3 \mathrm{~kg} / \mathrm{m}^{2}(S D=12.8)$. Patient baseline assessment revealed the following lifetime (current) comorbid diagnoses: major depressive disorder $72.7 \%(18.2 \%)$; dysthymia 9.1\%(0\%); alcohol abuse disorder $36.4 \%(0 \%)$; generalized anxiety disorder (27.3\% current only); panic disorder 19.2\%(0\%); social phobia $27.3 \%(27.3 \%)$; specific phobia $18.2 \%(18.2 \%)$; post-traumatic stress disorder 9.1\%(9.1\%). Personality disorders were not assessed.

\section{1 | Feasibility and acceptability}

Over 1 year, 23 couples inquired, and 11 were enrolled (See Supplementary Information Figure S1 for CONSORT diagram). Ten couples completed treatment ( $\geq 18$ sessions), and one (9\%) who had an undisclosed diagnosis rendering treatment untenable dropped out. UNITE was acceptable to the majority of couples. Mean CSQ-8 score for patients and partners was 27.44, SD 4.92 (Figure 1). All participants reported that UNITE-BED helped them deal more effectively with BED and support one another in the recovery process; $81.8 \%$ of participants reported the amount of treatment was just right. Free text items revealed unanimously positive responses to the focus on communication skills. Other than reducing survey burden, no consistent themes for improving UNITE-BED emerged.

\section{2 | Preliminary efficacy}

\subsection{1 | Eating disorder psychopathology}

At baseline, 10/11 patients reported recurrent OBEs in the last month. One patient had only SBEs in the last month (with OBEs in the recent past). For participants who reported recurrent OBEs at baseline $(N=10)$, $80 \%$ were OBE abstinent at post-treatment and $80 \%$ were OBE remitted (both 60\% at follow-up) (see definitions in Method above). The patient with SBEs only was in SBE remission at post-treatment and reported only one SBE at 3-month follow-up. The total number of OBEs in the prior 28 days decreased significantly from pre-to post-treatment (EDE, $M=11.4, S D=11.02$ vs. $M=.9, S D=2.51, t[9], 3.35, p=.009)$. SBEs did not change significantly (EDE, $M=2.10, S D=4.70$ vs. $M=1.20$, $S D=1.48, t[9]=.62, p=.55$ ). General ED symptom severity (EDE, BES, and Y-BOCS-BE) decreased significantly across all time points (Table 1).

\subsubsection{Patient and partner mood and emotion regulation}

Patient BDI-II scores decreased significantly from pre- to posttreatment and from pre-treatment to 3-month follow-up. Both patients and partners reported that the patients' emotion regulation significantly improved from pre- to post-treatment, and patients reported improvement from pre-treatment to follow-up. BAI scores did not change significantly for patients across time.

Partners displayed no significant shifts in BDI, BAl, or selfreported DERS scores across time. However, patients reported that partners significantly improved on emotion regulation (DERS-P) from pre- to post-treatment, although not at follow-up. Partners' pretreatment mean BDI and $\mathrm{BAI}$ scores were in the healthy range except for one partner who improved from mild at baseline to minimal at post-treatment. No partners had above normal anxiety scores.

\subsection{3 | Interpersonal functioning}

Patients and partners reported significantly improved affective communication from pre- to post-treatment. Relationship adjustment and other communication domains did not change significantly across time. Pre-treatment mean scores in the "satisfied" range (10/11) were maintained across treatment. One couple transitioned from "dissatisfied" at pre-treatment to "satisfied" at post-treatment.

\section{5 | DISCUSSION}

This is the first report on feasibility and acceptability of a couplebased intervention for BED. UNITE-BED was feasible and highly acceptable to couples. Dropout (9\%) was on the low end of psychotherapy trials for BED (4-34\%) (Brownley, 2016; de Zwaan et al., 2017; Safer, Robinson, \& Jo, 2010).

Although we cannot attribute all observed change to UNITE-BED since patients were in individual treatment of varying intensity and quality, UNITE-BED may contribute to clinical improvement. Binge-eating abstinence and remission rates were good at post-treatment and follow-up. When considering only threshold BED cases $(N=10)$, the OBE abstinence rate of $80 \%$ is encouraging, and higher than reported in larger trials (50.9 total weighted percentage; Linardon, 2018). UNITEBED also may have benefits beyond the ED. Whereas CBT for BED typically is not associated with significant reductions in depression (Brownley et al., 2016), our patients had significantly decreased BDI scores from pre- to post-treatment that were maintained at follow-up. Patients and partners also reported improved emotion regulation in patients. Given the high comorbidity between BED and depression (Welch et al., 2016) and the role of intense emotions in binge eating (Leehr et al., 2015), improvements in these domains are promising.

Partners did not demonstrate changes in emotional well-being, likely due to being non-distressed at pre-treatment and remaining stable over time. Likewise, couples were generally satisfied in their relationships at pre-treatment and remained so throughout. However, patients and partners reported feeling more satisfied with the amount of affection and understanding expressed by their partners. As helping couples better listen to and support one another around the ED was a primary goal, improvements in this domain are encouraging.

Overall, UNITE-BED may be a beneficial treatment for couples affected by BED. Involving partners may facilitate patients' improvements in several ways. First, partners may offer support and accountability in terms of remaining in treatment. Second, by educating 
TABLE 1 Mean scores (standard deviations) on treatment outcome variables from pre- to post-treatment and 3-month follow up, test statistics (paired sample $t$ tests for patient only continuous variables, two-way ANOVAs for measures completed by both partners, effect sizes) and Cronbach's alphas for each measure by time point

\begin{tabular}{|c|c|c|c|c|c|}
\hline Outcome & $\begin{array}{l}\text { Pre } \\
\text { M (SD) } \\
\text { [Cronbach's } \\
\text { alpha] }\end{array}$ & $\begin{array}{l}\text { Post } \\
\text { M (SD) } \\
\text { [Cronbach's } \\
\text { alpha] }\end{array}$ & $\begin{array}{l}\text { Pre vs. post test } \\
\text { Statistic }^{\mathrm{a}} \\
95 \% \mathrm{Cl}[\mathrm{U}, \mathrm{L}], \mathrm{ES}^{\mathrm{b}}\end{array}$ & $\begin{array}{l}3 \text { Month follow up } \\
\text { M (SD) } \\
\text { [Cronbach's } \\
\text { alpha] }\end{array}$ & $\begin{array}{l}\text { Pre vs. } 3 \text { Month } \\
\text { follow-up test } \\
\text { Statistic } \\
95 \% \mathrm{Cl}[\mathrm{U}, \mathrm{L}], \mathrm{ES}^{\mathrm{b}}\end{array}$ \\
\hline \multicolumn{6}{|l|}{$\begin{array}{l}\text { Eating disorder } \\
\text { psychopathology }\end{array}$} \\
\hline $\begin{array}{l}\text { EDE global score-patient } \\
\text { ( } 23 \text { items) }\end{array}$ & $\begin{array}{l}3.02(1.22) \\
{[\alpha=.90]}\end{array}$ & $\begin{array}{l}1.55(.95) \\
{[\alpha=.89]}\end{array}$ & $\begin{array}{l}\mathrm{t}(10)=4.83 * *, 95 \% \\
\quad \mathrm{Cl}[.71,1.94], d=1.48\end{array}$ & $\begin{array}{l}1.95(1.16) \\
{[\alpha=.89]}\end{array}$ & $\begin{array}{l}t(11)=3.60 * *, 95 \% \\
\quad \mathrm{Cl}[.42,1.72], d=1.03\end{array}$ \\
\hline BES-patient (16 items) & $\begin{array}{l}28.18(9.16) \\
{[\alpha=.91]}\end{array}$ & $\begin{array}{l}13.70(8.69) \\
{[\alpha=.91]}\end{array}$ & $\begin{array}{l}t(9)=3.87 * *, 95 \% \\
\quad C I[5.44,20.76], d=1.22\end{array}$ & $\begin{array}{l}15.09(9.65) \\
{[\alpha=.92]}\end{array}$ & $\begin{array}{l}t(10)=4.98 * *, 95 \% \\
\quad \operatorname{Cl}[7.23,18.95], d=1.50\end{array}$ \\
\hline $\begin{array}{l}\text { YBOCS-BE-patient } \\
\text { (10 items) }\end{array}$ & $\begin{array}{l}19.00(5.13) \\
{[\alpha=.81]}\end{array}$ & $\begin{array}{l}9.36(6.93) \\
{[\alpha=.94]}\end{array}$ & $\begin{array}{l}t(10)=4.31 * *, 95 \% \\
\quad \text { CI }[4.26,13.37], d=1.36\end{array}$ & $\begin{array}{l}8.83(7.37) \\
{[\alpha=.89]}\end{array}$ & $\begin{array}{l}t(11)=5.77 * * *, 95 \% \\
\quad C I[6.29,14.04], d=1.76\end{array}$ \\
\hline \multicolumn{6}{|l|}{ Other psychopathology } \\
\hline BDI-patient (21 items) & $\begin{array}{l}17.45(11.35) \\
{[\alpha=.92]}\end{array}$ & $\begin{array}{l}8.00(7.13) \\
{[\alpha=.86]}\end{array}$ & $\begin{array}{l}t(9)=3.44 * *, 95 \% \\
\quad C I[2.29,11.11], d=1.07\end{array}$ & $\begin{array}{l}11.00(14.94) \\
{[\alpha=.98]}\end{array}$ & $\begin{array}{l}t(10)=2.68 *, 95 \% \\
\quad \mathrm{Cl}[1.08,11.82], \text { Cohen's } d=.89\end{array}$ \\
\hline BDI-partner (21 items) & $\begin{array}{l}5.64(4.95) \\
{[\alpha=.87]}\end{array}$ & $\begin{array}{l}5.52(4.13) \\
{[\alpha=.77]}\end{array}$ & $\begin{array}{l}t(9)=.49, p=.64,95 \% \\
\quad C l[-2.49,3.86], d=.15\end{array}$ & $\begin{array}{l}5.00(4.54) \\
{[\alpha=.86]}\end{array}$ & $\begin{array}{l}t(10)=.39, p=.70,95 \% \\
\quad C l[-2.96,4.23], d=.11\end{array}$ \\
\hline BAl-patient (21 items) & $\begin{array}{l}9.82(11.23) \\
{[\alpha=. .94]}\end{array}$ & $\begin{array}{l}6.50(5.84) \\
{[\alpha=.85]}\end{array}$ & $\begin{array}{l}F(1,9)=.82, p=.39 \\
\eta^{2}=.008\end{array}$ & $\begin{array}{l}12.64(15.38) \\
{[\alpha=.97]}\end{array}$ & $F(1,10)=1.67, p=.23, \eta^{2}=.003$ \\
\hline BAI-partner (21 items) & $\begin{array}{l}2.45(3.45) \\
{[\alpha=.85]}\end{array}$ & $\begin{array}{l}1.40(1.78) \\
{[\alpha=.50]}\end{array}$ & & $\begin{array}{l}1.91(4.46) \\
{[\alpha=.96]}\end{array}$ & $F(1,10)=1.67, p=.23, \eta^{2}=.003$ \\
\hline DERS-patient (36 items) & $\begin{array}{l}92.00(26.35) \\
{[\alpha=.95]}\end{array}$ & $\begin{array}{l}68.7(20.38) \\
{[\alpha=.93]}\end{array}$ & $\begin{array}{l}t(9)=4.32 * *, 95 \% \\
\quad C l[8.81,28.19], d=1.37\end{array}$ & $\begin{array}{l}77.55(29.50) \\
{[\alpha=.97]}\end{array}$ & $\begin{array}{l}t(10)=3.17 *, 95 \% \\
\quad \mathrm{Cl}[4.29,24.61], d=.97\end{array}$ \\
\hline DERS-partner (36 items) & $\begin{array}{l}59.64(6.92) \\
{[\alpha=.61]}\end{array}$ & $\begin{array}{l}61.70(13.92) \\
{[\alpha=.87]}\end{array}$ & $\begin{array}{l}t(9)=-.47, p=.65,95 \% \\
\quad C l[-11.02,7.23], d=-.16\end{array}$ & $\begin{array}{l}62.64(20.09) \\
{[\alpha=.96]}\end{array}$ & $\begin{array}{l}t(10)=-.54, p=.60,95 \% \\
\quad \mathrm{Cl}[-15.36,9.36], d=-.20\end{array}$ \\
\hline DERS-P-patient (8 items) & $\begin{array}{l}13.45(4.16) \\
{[\alpha=.31]}\end{array}$ & $\begin{array}{l}11.40(3.41) \\
{[\alpha=.84]}\end{array}$ & $F(1,9)=12.63^{* *}, \eta^{2}=.046$ & $\begin{array}{l}11.82(3.28) \\
{[\alpha=.73]}\end{array}$ & $F(1,10)=.79, p=.40, \eta^{2}=.006$ \\
\hline DERS-P-partner (8 items) & $\begin{array}{l}16.45(5.28) \\
{[\alpha=.86]}\end{array}$ & $\begin{array}{l}15.00(4.81) \\
{[\alpha=.86]}\end{array}$ & & $\begin{array}{l}16.55(5.34) \\
{[\alpha=.80]}\end{array}$ & \\
\hline \multicolumn{6}{|l|}{ Interpersonal functioning } \\
\hline DAS-patient (4 items) & $\begin{array}{l}109.46(12.46) \\
{[\alpha=.88]}\end{array}$ & $\begin{array}{l}115.80(6.55) \\
{[\alpha=.63]}\end{array}$ & $\begin{array}{c}F(1,9)=2.08, p=.18 \\
\eta^{2}=.031\end{array}$ & $\begin{array}{l}107.45(13.68) \\
{[\alpha=.90]}\end{array}$ & $F(1,10)=.53, p=.49, \eta^{2}=.008$ \\
\hline DAS-partner (4 items) & $\begin{array}{l}112.91(9.74) \\
{[\alpha=.83]}\end{array}$ & $\begin{array}{l}112.80(8.80) \\
{[\alpha=.66]}\end{array}$ & & $\begin{array}{l}111.00(8.75) \\
{[\alpha=.60]}\end{array}$ & \\
\hline CPQdw-patient (6 items) & $\begin{array}{l}18.91(7.82) \\
{[\alpha=.60]}\end{array}$ & $\begin{array}{l}15.40(9.83) \\
{[\alpha=.87]}\end{array}$ & $\begin{array}{c}F(1,9)=3.91, p=.08 \\
\eta^{2}=.044\end{array}$ & $\begin{array}{l}17.82(8.84) \\
{[\alpha=.86]}\end{array}$ & $F(1,10)=.35, p=.57, \eta^{2}=.003$ \\
\hline CPQdw-partner (6 items) & $\begin{array}{l}16.18(10.00) \\
{[\alpha=.78]}\end{array}$ & $\begin{array}{l}13.60(6.93) \\
{[\alpha=.77]}\end{array}$ & & $\begin{array}{l}15.27(9.65) \\
{[\alpha=.93]}\end{array}$ & \\
\hline CPQcomm-patient (5 items) & $\begin{array}{l}32.82(9.69) \\
{[\alpha=.84]}\end{array}$ & $\begin{array}{l}35.30(6.29) \\
{[\alpha=.60]}\end{array}$ & $\begin{array}{l}F(1,9)=.64, p=.44 \\
\eta^{2}=.011\end{array}$ & $\begin{array}{l}33.09(8.88) \\
{[\alpha=.91]}\end{array}$ & $F(1,10)=.43, p=.53, \eta^{2}=.004$ \\
\hline CPQcomm-partner (5 items) & $\begin{array}{l}36.73(6.92) \\
{[\alpha=.77]}\end{array}$ & $\begin{array}{l}37.40(4.72) \\
{[\alpha=.75]}\end{array}$ & & $\begin{array}{l}34.45(6.42) \\
{[\alpha=.69]}\end{array}$ & \\
\hline MSIpsc-patient (19 items) & $\begin{array}{l}6.82(5.83) \\
{[\alpha=.93]}\end{array}$ & $\begin{array}{l}4.60(3.10) \\
{[\alpha=.76]}\end{array}$ & $\begin{array}{c}F(1,9)=.56, p=.47 \\
\eta^{2}=.007\end{array}$ & $\begin{array}{l}4.73(4.15) \\
{[\alpha=.86]}\end{array}$ & $\begin{array}{c}t(10)=1.87 ; p=.09,95 \% \\
\mathrm{Cl}[-1.39,4.58], d=.62\end{array}$ \\
\hline MSIpsc-partner (19 items) & $\begin{array}{l}5.55(5.37) \\
{[\alpha=.92]}\end{array}$ & $\begin{array}{l}5.10(4.82) \\
{[\alpha=.90]}\end{array}$ & & $\begin{array}{l}7.45(6.02) \\
{[\alpha=.93]}\end{array}$ & $\begin{array}{c}t(10)=-1.36, p=.20,95 \% \\
\text { CI }[-5.03,1.21], d=-.41\end{array}$ \\
\hline MSlafc-patient (12 items) & $\begin{array}{l}5.00(3.74) \\
{[\alpha=87]}\end{array}$ & $\begin{array}{l}3.1(2.69) \\
{[\alpha=.75]}\end{array}$ & $\begin{array}{c}F(1,9)=17.61 * * \\
\eta^{2}=.062\end{array}$ & $\begin{array}{l}3.64(3.59) \\
{[\alpha=.87]}\end{array}$ & $F(1,10)=2.36, p=.16, \eta^{2}=.011$ \\
\hline MSlafc-partner (12 items) & $\begin{array}{l}3.00(2.93) \\
{[\alpha=.82]}\end{array}$ & $\begin{array}{l}2.00(2.31) \\
{[\alpha=.76]}\end{array}$ & & $\begin{array}{l}3.00(2.76) \\
{[\alpha=.78]}\end{array}$ & \\
\hline
\end{tabular}

Note. $\mathrm{EDE}=$ Eating Disorders Examination; $\mathrm{BES}=$ Binge-Eating Scale; $\mathrm{YBOCS}-\mathrm{BE}=$ Yale Brown Obsessive Compulsive Scale Modified for Binge Eating; $\mathrm{BDI}=$ Beck Depression Inventory; BAI = Beck Anxiety Inventory; DERS = Difficulties in Emotion Regulation Scale; DAS = Dyadic Adjustment Scale; $\mathrm{CPQ}=$ Communication Patterns Questionnaire $(-\mathrm{dw}=$ demand withdrawal; - comm = constructive communication); MSI = Marital Satisfaction Index $(-$ psc $=$ problem solving communication; - afc $=$ affective communication $)$.

${ }^{a}$ All hypotheses were tested using 2 (patient vs. partner) $\times 2$ (time) repeated-measures ANOVAs. F-test statistics reported in the table are main effects for time. If the time $X$ patient interaction emerged as significant in a repeated-measure ANOVA, the interaction was decomposed using paired samples $t$ tests, which are reported in the table. $p<.05 . * * p<.01 * * * p<.001$.

${ }^{\mathrm{b}} \mathrm{ES}=$ Effect Size. Effect sizes were calculated using eta squared for repeated measures ANOVAs (Olejnik \& Algina, 2003) and Cohen's $d$ with Morris and DeShon's (2002) Equation 8 applied for paired samples $t$ tests. See Cohen, 1988 for interpretation of effect sizes. Given the small sample size, effect sizes may be upwardly biased (Ferguson, 2009). 


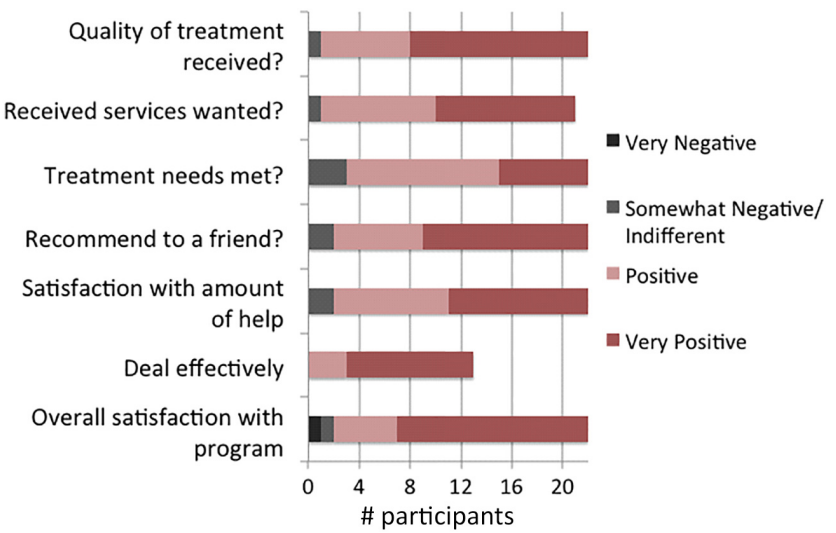

FIGURE 1 Acceptability: Post-treatment feedback survey results $(N=22)$ Footer: The numbers on the horizontal axis indicate the number of participant responses to an individual item. Pink indicates a positive response, and grey indicates a negative response. Both patient and partner responses are included, except for the item about the individual dealing effectively with BED which only includes patient responses. Partners were asked an equivalent question with data presented in text [Color figure can be viewed at wileyonlinelibrary.com]

partners on BED treatment targets and guiding targeted couple discussions, the broader eating context is addressed and may help reduce restriction and binge-eating triggers. Third, UNITE-BED focuses on improving couples' ability to communicate around the ED, sharing thoughts and feelings, and making decisions as a team, which help couples counter avoidance of the disorder. By skillfully sharing emotional experiences with partners, patients may feel less isolated or overwhelmed by urges and feelings and be less likely to binge eat to regulate emotions. Whether other family members could be engaged in adult ED treatment is unknown, although we are studying the feasibility of this approach (Reyes-Rodríguez, Baucom, \& Bulik, 2014).

Our findings are tentative given the small sample size, absence of a control group, and inclusion of independent individual treatment. We cannot attribute all improvements to UNITE-BED rather than the individual treatment received or simply greater therapist contact. We aim next to compare UNITE-BED as a stand-alone treatment to individual CBT. Further, our sample may not reflect the general BED population given these were stable relationships and included couples who self-selected to participate. In conclusion, pilot results of UNITEBED are very promising and support larger controlled investigations including partners in BED treatment.

\section{ACKNOWLEDGMENTS}

We would like to thank Jennifer Belus and McKenzie Roddy for their contributions to this research. Dr. Runfola was supported by the Global Foundation for Eating Disorders (PIs: Bulik \& Baucom). UNITE is also supported by a grant from the Hilda and Preston Davis Foundation. Dr. Bulik is a grant recipient and has served on advisory boards for Shire Pharmaceuticals and acknowledges funding from the Swedish Research Council (VR Dnr: 538-2013-8864).

\section{REFERENCES}

Agh, T., Kovacs, G., Supina, D., Pawaskar, M., Herman, B. K., Voko, Z., \& Sheehan, D. V. (2016). A systematic review of the health-related quality of life and economic burdens of anorexia nervosa, bulimia nervosa, and binge eating disorder. Eating and Weight Disorders, 21(3), 353-364. https://doi.org/10.1007/s40519-016-0264-x

APA. (2013). American Psychiatric Association. (DSM-5) diagnostic and statistical manual of mental disorders (5th ed.). Washington, DC: American Psychiatric Press, Inc.

Arcelus, J., Haslam, M., Farrow, C., \& Meyer, C. (2013). The role of interpersonal functioning in the maintenance of eating psychopathology: A systematic review and testable model. Clinical Psychology Review, 33(1), 156-167. https://doi.org/10.1016/j.cpr.2012.10.009

Baucom, D. H., Kirby, J. S., Fischer, M. S., Baucom, B. R., Hamer, R., \& Bulik, C. M. (2017). Findings from a couple-based open trial for adult anorexia nervosa. Journal of Family Psychology, 31(5), 584-591. https://doi.org/10.1037/fam0000273

Blomquist, K. K., Ansell, E. B., White, M. A., Masheb, R. M., \& Grilo, C. M. (2012). Interpersonal problems and developmental rajectories of binge eating disorder. Comprehensive Psychiatry, 53(8), 1088-1095. https:// doi.org/10.1016/j.comppsych.2012.05.003

Brownley, K. A., Berkman, N. D., Peat, C. M., Lohr, K. N., Cullen, K. E., Bann, C. M., \& Bulik, C. M. (2016). Binge eating disorder in adults: A systematic review and meta-analysis. Annals of Internal Medicine, 165(6), 409-420. https://doi.org/10.1002/eat.20370

Bulik, C. M., Berkman, N. D., Brownley, K. A., Sedway, J. A., \& Lohr, K. N. (2007). Anorexia nervosa treatment: A systematic review of randomized controlled trials. International Journal of Eating Disorders, 40, 310-320. https://doi.org/10.1891/0889-8391.26.1.19

Cohen, J. (1988). Statistical power analysis for the behavioral sciences (2nd ed.). Hillsdale, NJ: Lawrence Erlbaum.

de Zwaan, M., Herpertz, S., Zipfel, S., Svaldi, J., Friederich, H., Schmidt, F., ... Hilbert, A. (2017). Effect of internet-based guided self-help vs. individual face-to-face treatment on full or subsyndromal binge eating disorder in overweight or obese patients: The INTERBED randomized clinical trial. JAMA Psychiatry, 74(10), 987-995. https://doi.org/10.1001/ jamapsychiatry.2017.2150

Epstein, N. B., \& Baucom, D. H. (2002). Enhanced cognitive-behavioral therapy for couples: A contextual approach. Washington, DC: American Psychological Association.

Fairburn, C. G., Cooper, Z., \& Shafran, R. (2003). Cognitive behaviour therapy for eating disorders: A "transdiagnostic" theory and treatment. Behaviour Research and Therapy, 41(5), 509-528. https://doi.org/10. 1016/S0005-7967(02)00088-8

Ferguson, C. J. (2009). An effect size primer: A guide for clinicians and researchers. Professional Psychology: Research and Practice, 40(5), 532-538. https://doi.org/10.1037/a0015808

Grilo, C. M. (2017). Psychological and behavioral treatments for binge-eating disorder. Journal of Clinical Psychiatry, 78(Suppl 1), 20-24. https://doi.org/10.4088/JCP.sh16003su1c.04

Hilbert, A., Vogele, C., Tuschen-Caffier, B., \& Hartmann, A. S. (2011). Psychophysiological responses to idiosyncratic stress in bulimia nervosa and binge eating disorder. Physiology \& Behavior, 104(5), 770-777. https://doi.org/10.1016/j.physbeh.2011.07.013

International Committee of Medical Journal Editors (ICMJE). (2010). Uniform requirements for manuscripts submitted to biomedical journals: Writing and editing for biomedical publications. Journal of Pharmacological Pharmacotherapy, 1(1), 42-58.

Jones, A., Lindekilde, N., Lübeck, M., \& Clausen, L. (2015). The association between interpersonal problems and treatment outcome in the eating disorders: A systematic review. Nordic Journal of Psychiatry, 69(8), 563-573. https://doi.org/10.3109/08039488.2015.1019924

Kirby, J. S., Runfola, C. D., Fischer, M. S., Baucom, D. H., \& Bulik, C. M. (2015). Couple-based treatment for eating disorders. Eating Disorders: The Journal of Treatment and Prevention. Special Edition, 23(4), 356-365. https://doi.org/10.1080/10640266.2015.1044349

Kirby, J. S., Runfola, C. D., Fischer, M. S., Baucom, D. H., \& Bulik, C. M. (2016). Couple-based interventions for adults with eating disorders. In S. Murray, L. Anderson, \& L. Cohn (Eds.), Innovations in family therapy 
for eating disorders: Novel treatment developments, patient insights, and the role of Carers. Abingdon: Routledge.

Leehr, E. J., Krohmer, K., Schag, K., Dresler, T., Zipfel, S., \& Giel, K. E. (2015). Emotion regulation model in binge eating disorder and obesity-a systematic review. Neuroscience Biobehavioral Review, 49, 125-134. https://doi.org/10.1016/j.neubiorev.2014.12.008

Linardon, J. (2018). Rates of abstinence following psychological or behavioral treatments for binge-eating disorder: Meta-analysis. International Journal of Eating Disorders, 1-13. https://doi.org/10.1002/eat.22897

Linville, C., Cobb, E., Shen, F., \& Stadelman, S. (2015). Reciprocal influence of couple dynamics and eating disorders. Journal of Marital and Family Therapy, 42, 1-15. https://doi.org/10.1111/jmft.12133

Lock, J. (2015). An update on evidence-based psychosocial treatments for eating disorders in children and adolescents. Journal of Clinical Child \& Adolescent Psychology, 44(5), 707-721. https://doi.org/10.1080/15374416. 2014.971458

Macdonald, P., Rhind, C., Hibbs, R., Goddard, E., Raenker, S., Todd, G., ... Treasure, J. (2014). Carers' assessment, skills and information sharing (CASIS) trial: A qualitative study of the experiential perspective of caregivers and patients. European Eating Disorders Review, 22(6), 430-438. https://doi.org/10.1002/erv.2320

Morris, S. B., \& DeShon, R. P. (2002). Combining effect size estimates in meta-analysis with repeated measures and independent-groups designs. Psychological Methods, 7(1), 105-125. https://doi.org/10. 1037///1082.989X.7.1.105

Olejnik, S., \& Algina, J. (2003). Generalized eta and omega squared statistics. Psychological Methods, 8(4), 434-437. https://doi.org/10. 1037/1082-989X.8.4.434

Reyes-Rodríguez, M. L., Baucom, D. H., \& Bulik, C. M. (2014). Culturally sensitive intervention for Latina women with eating disorders: A case study. Review Mex Trastor Aliment, 5(2), 136-146. https://doi.org/10. 1016/S2007-1523(14)72009-9

Safer, D. L., Robinson, A. H., \& Jo, B. (2010). Outcome from a randomized controlled trial of group therapy for binge eating disorder: Comparing dialectical behavior therapy adapted for binge eating to an active comparison group therapy. Behavior Therapy, 41(1), 106-120. https://doi. org/10.1016/j.beth.2009.01.006

Schlup, B., Meyer, A. H., \& Munsch, S. (2010). A non-randomized direct comparison of cognitive-behavioral short- and long-term treatment for binge eating disorder. Obeitys Facts, 3(4), 261-266. https://doi.org/10. $1159 / 000319538$

Welch, E., Jangmo, A., Thornton, L., Herman, B., Pawaskar, M., Larsson, H., \& Bulik, C. M. (2016). Treatment-seeking patients with binge-eating disorder in the Swedish national registers: Clinical course and psychiatric comorbidity. BMC Psychiatry, 16, 163. https://doi. org/10.1186/s12888-016-0840-7

Whisman, M. A., Demetyeva, A., Baucom, D. H., \& Bulik, C. M. (2012). Marital functioning and binge eating disorder in married women. International Journal of Eating Disorders, 45(3), 385-389. https://doi.org/10. 1002/eat.20935

White, I. R., Horton, N. J., Carpenter, J., \& Pocock, S. J. (2011). Strategy for intention to treat analysis in randomised trials with missing outcome data. The BMJ, 342, d40. https://doi.org/10.1136/bmj.d40

\section{SUPPORTING INFORMATION}

Additional supporting information may be found online in the Supporting Information section at the end of the article.

How to cite this article: Runfola CD, Kirby JS, Baucom DH, et al. A pilot open trial of UNITE-BED: A couple-based intervention for binge-eating disorder. Int J Eat Disord. 2018;51: 1107-1112. https://doi.org/10.1002/eat.22919 